Research article

\title{
A two-step pH control method to remove divalent metals from near-neutral mining and metallurgical waste drainages by inducing the formation of layered double hydroxide
}

\author{
Franco Frau $^{\text {a, }}{ }^{*}$, Roberta Atzori ${ }^{a}$, Carla Ardau ${ }^{a}$, Daniela Medas ${ }^{a}$, Francesca Podda ${ }^{a}$, \\ Elisabetta Dore $^{\mathrm{a}}$, Alfredo Idini ${ }^{\mathrm{a}}$, Gioacchino Tempesta ${ }^{\mathrm{b}}$, Giovanna Agrosì ${ }^{\mathrm{b}}$ \\ ${ }^{a}$ Department of Chemical and Geological Sciences, University of Cagliari, Cagliari, Italy \\ ${ }^{\mathrm{b}}$ Department of Earth and Geoenvironmental Sciences, University of Bari, Bari, Italy
}

\section{A R T I C L E I N F O}

\section{Keywords:}

Near-neutral metal polluted drainage

LDH precipitation

HRTEM and XAS analyses

Metal removal

Role of Al-hydroxysulfate

$\mathrm{pH}$ constraint

\begin{abstract}
A B S T R A C T
A neutral $\mathrm{M}^{2+}$-rich and $\mathrm{M}^{3+}$-poor $(\mathrm{M}=$ metal) metallurgical waste drainage was used to test a metal removal method based on the precipitation of layered double hydroxide (LDH). The LDH precipitation was induced by adding a salt of $\mathrm{Al}^{3+}$ (trivalent metal missing in the drainage) and maintaining or restoring the $\mathrm{pH}$ to a circumneutral value. The precipitates were characterized by chemical analysis, XRD, ESEM, HRTEM and XAS. The main parameter controlling the removal of metals and the type of precipitate appeared to be the $\mathrm{pH}$. As a function of $\mathrm{pH}$ variation during the experiments, analyses of precipitates and solutions showed either the formation of poor crystalline LDH combined with very high removal of $\mathrm{Zn}$, Ni and $\mathrm{Pb}$ (92-100\%), more variable removal of Mn (46-98\%) and less Cd (33-40\%), or the formation of more crystalline LDH combined with lower removal of Zn (62\%), Mn (43\%), Ni (88\%), Pb (64\%) and especially Cd (1\%). The different metal removal efficiency in the two cases is only indirectly due to the different LDH crystallinity, and it is clearly affected by the following factors: 1) the two $\mathrm{pH}$ steps of the method; 2) the direction of $\mathrm{pH}$ variation within each step. In particular, the highest removal of metals is obtained when the first $\mathrm{pH}$ step goes towards acidic conditions, as a consequence of $\mathrm{Al}$ salt addition, and precipitation of a quasi-amorphous hydrated hydroxysulfate of $\mathrm{Al}$ (probably a precursor of felsöbányaite $\mathrm{Al}_{4}\left(\mathrm{SO}_{4}\right)(\mathrm{OH})_{10} \cdot 4 \mathrm{H}_{2} \mathrm{O}$ ) occurs. This first acidic pH step removes little or no metals (just 0-3\%) but it is essential so that the second $\mathrm{pH}$ step towards slightly alkaline conditions, as a consequence of $\mathrm{NaOH}$ addition, can be highly efficient in removing divalent metals as the quasi-amorphous hydrated hydroxysulfate of $\mathrm{Al}$ gradually turns into an LDH incorporating $\mathrm{Zn}, \mathrm{Mg}$ and other metals. On the contrary, when both pH steps remain in the neutral-alkaline range, only LDH precipitation occurs and a lower metal removal is observed. These results encourage further investigations on the removal of metals by inducing LDH precipitation as a simple and effective method for the treatment of circum-neutral polluted drainages.
\end{abstract}

\section{Introduction}

Acid mine drainage (AMD) is a worldwide issue and there is a vast scientific literature on the numerous active and passive treatment methods based on different mechanisms and materials (Johnson and Hallberg, 2005; Sheoran and Sheoran, 2006; RoyChowdhury et al., 2015; Sanchez-España and Yusta, 2015, 2019; Kefeni et al., 2017; Skousen et al., 2017; Saha and Sinha, 2018; Park et al., 2019). Also near-neutral mining and metallurgical waste drainages often are of environmental concern because, despite non-acidic conditions, some dissolved metals and metalloids may reach high concentrations and, thus, represent a hazard for integrity of ecosystems and human health (Banks et al., 1997; Iribar, 2004; Lindsay et al., 2009; Medas et al., 2014a, 2014b; Frau et al., 2015; Nordstrom et al., 2015; Calugaru et al., 2018; De Giudici et al., 2018). Divalent metals such as Zn, Cd and Mn are generally stable in circum-neutral solutions owing to $\mathrm{pH}$ adsorption edges higher than those of other divalent metals such as $\mathrm{Pb}$ and $\mathrm{Cu}$ with respect to common adsorbent phases (e.g., hydrous ferric oxides, HFO) (Smith, 1999). Also toxic metalloids, such as As and Sb that form oxyanions, may occur at relatively high concentrations because they are

\footnotetext{
* Corresponding author.

E-mail address: frauf@unica.it (F. Frau).
} 
very stable in neutral-alkaline solutions and tend to be desorbed from HFO and other sorbent phases rather than adsorbed (Frau and Ardau, 2004; Leuz et al., 2006; Frau et al., 2008, 2010; 2012; Hu et al., 2016).

The treatment of circum-neutral metal polluted drainages even today represents a challenge, especially if a low-cost, simple and effective method is the goal to be pursued (Calugaru et al., 2018). Layered double hydroxides (LDH) are lamellar compounds with general formula $\left[\mathrm{M}^{2+}{ }_{1-\mathrm{x}}\right.$ $\left.\mathrm{M}^{3+}{ }_{\mathrm{x}}(\mathrm{OH})_{2}\right]\left(\mathrm{A}^{\mathrm{n}-}\right)_{\mathrm{x} / \mathrm{n}} \cdot \mathrm{mH}_{2} \mathrm{O}$, where $\mathrm{M}^{2+}$ are divalent metals (e.g., $\mathrm{Mg}^{2+}, \mathrm{Zn}^{2+}, \mathrm{Fe}^{2+}, \mathrm{Cu}^{2+}$, etc.), $\mathrm{M}^{3+}$ are trivalent metals (e.g., $\mathrm{Al}^{3+}, \mathrm{Fe}^{3+}$, etc.), $\mathrm{A}^{\mathrm{n}-}$ are anions such as $\mathrm{CO}_{3}^{2-}, \mathrm{SO}_{4}^{2-}$ and $\mathrm{Cl}^{-}$, and $\mathrm{x}$ is the $\mathrm{M}^{3+} /\left(\mathrm{M}^{3+}\right.$ $+\mathrm{M}^{2+}$ ) molar ratio (Cavani et al., 1991). The LDH structure is characterized by positive octahedral brucite-like layers, where the excess of positive charge is due to the isomorphic substitution of $\mathrm{M}^{2+}$ with $\mathrm{M}^{3+}$, alternating with negative interlayers containing anions and a variable quantity of water (Cavani et al., 1991). These compounds are widely studied, both untreated and calcined, for the removal of anionic pollutants from water thanks to the high anion exchange capacity of untreated phases and the high sorption capacity of calcined ones (Li and Duan, 2006; Carriazo et al., 2007; Goh et al., 2008; Lv et al., 2009; Ardau et al., 2011, 2012; 2013, 2016; Kameda et al., 2015; Dore and Frau, 2018, 2019; Dore et al., 2019). Moreover, LDH can be effective removers of cationic pollutants by (co)precipitation and adsorption (Park et al., 2007; Liang et al., 2013). LDH precipitation generally presupposes neutral-alkaline conditions and the presence of dissolved divalent and trivalent metals in adequate ratios, and therefore it is a potential mechanism suitable for the decontamination of near-neutral mining and metallurgical waste drainages.

Drainages from the impoundment of "Red Muds" (metallurgical wastes from an electrolytic plant processing oxidized Zn-ores) in the Monteponi mine area (Iglesias, SW Sardinia, Italy) represent a paradigmatic case of polluted metal-rich solutions with a strongly deleterious impact on the quality of the receiving water course (i.e., Rio San Giorgio; De Giudici et al., 2017). The "Red Muds" drainage is characterized by neutral $\mathrm{pH}$ and high levels of divalent metals (e.g., 550-7100 $\mathrm{mg} / \mathrm{L} \mathrm{Zn}^{2+}, 2.4-23 \mathrm{mg} / \mathrm{L} \mathrm{Cd}^{2+}, 0.9-1.4 \mathrm{mg} / \mathrm{L} \mathrm{Pb}^{2+;}$ Buosi et al., 2001), but very low concentrations of trivalent metals such as $\mathrm{Fe}^{3+}$ and $\mathrm{Al}^{3+}$ $(<10 \mu \mathrm{g} / \mathrm{L}$; Cidu et al., 2005). In order to eliminate or reduce this contamination source to the Rio San Giorgio catchment, the treatment of the "Red Muds" drainage has been thought to be realized taking advantage of the drainage composition that is particularly favourable to the precipitation of LDH by simply adding a trivalent metal missing in the drainage itself.

The general aim of this work is to propose a simple and effective decontamination method for drainage waters characterized by nearneutral $\mathrm{pH}$ and high divalent metals content. The specific aims are to identify the physico-chemical parameters controlling the type of precipitate linked to the removal of metals and understand the mechanism responsible for the metal removal efficiency. Moreover, the proposed treatment method is not only intended to be possibly applied in the local situation of the "Red Muds" impoundment, but it could be adaptable to different situations in which there are circum-neutral drainages with high concentrations of divalent metals and even metalloids, having LDH the ability to simultaneously remove contaminants in both cationic and anionic form.

This work does not claim to be all-encompassing, and focuses on laboratory experiments aimed at evaluating the efficacy of the method and understanding the mechanisms that govern the mineralogicalgeochemical processes involved. Future studies will be more devoted to refine and apply the treatment method: (i) using both synthetic and natural circum-neutral metal and metalloid polluted solutions, as well as different reagents; (ii) assessing the effectiveness and applicability in various conditions; (iii) providing information on treatment costs.

\section{Study area}

The "Red Muds" deposit mainly consists of metallurgical wastes from an electrolytic plant used in processing oxidized Zn-ores. The area occupied by the deposit of "Red Muds" is located within the so-called "Metalliferous Ring" in the Iglesiente mining district (south-west Sardinia, Italy) that covers approximately $150 \mathrm{~km}^{2}$ in the Cambrian limestone-dolomite formation (Pillola et al., 1998). This area was intensively exploited for the extraction of galena $(\mathrm{PbS})$, sphalerite ( $\mathrm{ZnS}$ ) and barite $\left(\mathrm{BaSO}_{4}\right)$, but also calamines mainly composed of hemimorphite $\left(\mathrm{Zn}_{4} \mathrm{Si}_{2} \mathrm{O}_{7}(\mathrm{OH})_{2} \cdot \mathrm{H}_{2} \mathrm{O}\right)$ and minor amounts of smithsonite $\left(\mathrm{ZnCO}_{3}\right)$ and hydrozincite $\left(\mathrm{Zn}_{5}\left(\mathrm{CO}_{3}\right)_{2}(\mathrm{OH})_{6}\right)$ (Boni, 1994).

The deposit of "Red Muds" has an area of about 70,000 $\mathrm{m}^{2}$ with an estimated volume of $800,000 \mathrm{~m}^{3}$ consisting of about 2 Mt of metallurgical wastes accumulated as a slurry in the period 1926-1983 (Supplementary Fig. S1). The deposit is arranged in terraces in which, besides the electrolytic plant wastes, other types of wastes are also present (i.e., foundry wastes, Waelz slags, mining waste-rocks, mine wastes from leaching, hydrogravimetric and magnetic treatments).

Most of materials accumulated in the "Red Muds" deposit are very fine in grain size and are affected by diffuse erosion and formation of ruts and gullies along the slopes, with consequent transport of contaminants in solid and liquid form. The wind erosion has been reduced by the deposition of a layer of dolomite gravel on the horizontal surfaces of the deposit. The underlying bedrock consists of limestones and shales.

The "Red Muds" contain high amounts of Fe (31.5 wt \%) and other metals such as $\mathrm{Zn}(8.8 \mathrm{wt} \%), \mathrm{Pb}(1.1 \mathrm{wt} \%)$, Cd (0.04 wt \%) and Mn (0.4 wt \%) (Buosi et al., 2001). The content of $\mathrm{Mn}$ is also due to the use of pyrolusite $\left(\mathrm{MnO}_{2}\right)$ in ore processing. The mineralogical composition of "Red Muds" mainly consists of goethite $(\mathrm{FeOOH})$, gypsum $\left(\mathrm{CaSO}_{4}\right.$. $\left.2 \mathrm{H}_{2} \mathrm{O}\right)$ and smithsonite, and minor amounts of dolomite $\left(\mathrm{CaMg}\left(\mathrm{CO}_{3}\right)_{2}\right)$, hemimorphite, calcite $\left(\mathrm{CaCO}_{3}\right)$, hematite $\left(\mathrm{Fe}_{2} \mathrm{O}_{3}\right)$, barite, quartz $\left(\mathrm{SiO}_{2}\right)$ and magnetite $\left(\mathrm{Fe}_{3} \mathrm{O}_{4}\right)$ (Biddau et al., 2001).

The waters that drain the "Red Muds" have near-neutral $\mathrm{pH}$ and a $\mathrm{Mg}-\mathrm{Ca}-\mathrm{Zn}-\mathrm{SO}_{4}$ composition (Cidu and Fanfani, 2002; Cidu et al., 2005). Excluding periods of intense rain, the drainage flow usually is very low $(<0.1 \mathrm{~L} / \mathrm{s})$, but its polluting load to the Rio San Giorgio (main river of the area) is very high. It was estimated an annual load to the Rio San Giorgio of $3000 \mathrm{~kg} \mathrm{Zn,} 150 \mathrm{~kg} \mathrm{Mn}, 90 \mathrm{~kg} \mathrm{Cd}$ and $20 \mathrm{~kg} \mathrm{~Pb}$ (Contini et al., 1999). Moreover, the dispersion of metals is traceable to several kilometres downstream from the source of pollution to the Sa Masa marsh (Boni et al., 1999).

The "Red Muds" deposit has been qualified as an archaeological industrial site and is subject to regulation for its protection and conservation, in spite of its high contamination potential. Various actions have been proposed and partly carried out for the safety of the surrounding environment, including (i) the landfill surface sealing, (ii) the renaturalization of the waterproofed surface by planting native shrubs, and (iii) the cleaning and regularization of the riverbed at the base of the landfill. It was also envisaged a system of containment of run-off water to reduce the downstream contamination. In fact, an adequate treatment of the "Red Muds" drainages would significantly reduce the amount of metals released to the Rio San Giorgio and the Iglesias valley.

\section{Materials and methods}

\subsection{Sampling and chemical analysis of drainage}

The "Red Muds" drainage was sampled from an erosion rut at the base of the deposit after a rainy period (Supplementary Fig. S2). Temperature, alkalinity, conductivity, $\mathrm{pH}$ and Eh (redox potential) were measured in the field. Alkalinity was measured by colorimetric titration method with hydrochloric acid and methyl orange as indicator. Conductivity, $\mathrm{pH}$ and Eh were measured potentiometrically with appropriate electrodes. In particular, the Eh was determined with a platinum electrode, and values were corrected against the ZoBell's solution (Nordstrom, 1977). Several litres of water for the metal removal experiments were filtered at $0.4 \mu \mathrm{m}$ (Nuclepore polycarbonate filters), collected in HDPE bottles and stored at $4{ }^{\circ} \mathrm{C}$ in the dark. 
Chemical analysis of major and minor cations was performed on acidified aliquots $\left(1 \% \mathrm{v} / \mathrm{v} \mathrm{HNO}_{3}\right.$ suprapure grade) by inductively coupled plasma optical emission spectrometry (ICP-OES) and quadrupole inductively coupled plasma mass spectrometry (ICP-MS). In order to estimate the accuracy and precision of chemical analysis and to evaluate the quality of data, the EnviroMAT-Drinking Water High (EPH-3, SCP Science, ref.140-025-032) reference solution was used. Anions were determined by ion chromatography (IC) on an unacidified aliquot.

\subsection{Metal removal experiments}

On the basis of the chemical composition of the "Red Muds" drainage (Table 1), the removal batch experiments were designed with the goal to induce the precipitation of a $\mathrm{ZnAl}-\mathrm{SO}_{4} \mathrm{LDH}$ from the drainage water through the addition of an adequate amount of a salt of $\mathrm{Al}$, i.e., $\mathrm{Al}_{2}\left(\mathrm{SO}_{4}\right)_{3}$ - $18 \mathrm{H}_{2} \mathrm{O}$ (Carlo Erba ${ }^{\circledR}$ ). The amount of salt of $\mathrm{Al}$ to be added was calculated for a $\mathrm{Zn} / \mathrm{Al}$ molar ratio of $2 / 1$, assuming that also $\mathrm{Mg}$ would enter the divalent metal site of $\mathrm{LDH}$ and $\mathrm{a}(\mathrm{Zn}+\mathrm{Mg}) / \mathrm{Al}$ molar ratio of about $3 / 1$ would be obtained in the precipitated $\mathrm{LDH}$, that is the best $\mathrm{M}^{2+} / \mathrm{M}^{3+}$ molar ratio tested for the removal of anionic contaminants by ZnAl-SO ${ }_{4}$ LDH (Ardau et al., 2011, 2012). The expected removal of other metals contained in the "Red Muds" drainage water (e.g., Mn, Cd, $\mathrm{Pb}$ and $\mathrm{Ni}$ ) was supposed to take place mainly through isomorphic substitution with $\mathrm{Zn}$ and $\mathrm{Mg}$ at the divalent metal site of $\mathrm{LDH}$, but other mechanisms (e.g., surface adsorption, surface precipitation) are also possible.

In order to control the solution $\mathrm{pH}$ during the experiments, $\mathrm{NaOH}$ was added to maintain or restore the $\mathrm{pH}$ to a neutral or slightly alkaline value (i.e., $\mathrm{pH}$ around 8) that is the optimal $\mathrm{pH}$ for the synthesis of ZnAl-SO 4 LDH (Ardau et al., 2011).

The removal experiments were conducted in a one-litre glass reactor equipped with a mechanical stirrer, a $\mathrm{pH}$ electrode for monitoring $\mathrm{pH}$ variations during the experiment and a peristaltic pump for pumping reagents (i.e., $\mathrm{NaOH}$ ) inside the reactor. In order to design the experiments, the computer program PHREEQC Interactive (Parkhurst and Appelo, 1999) was used to simulate and calculate the amounts of reagents necessary to obtain the desired $\mathrm{pH}$ values. Five different experiments were conducted:

Exp-1: addition of Al salt, causing $\mathrm{pH}$ lowering from 7 to about 4.2, followed by dropwise addition of $0.5 \mathrm{M} \mathrm{NaOH}$ to bring final $\mathrm{pH}$ to 8.3; duration $5 \mathrm{~h}$.

Exp-2: dropwise addition of $0.5 \mathrm{M} \mathrm{NaOH}$, causing $\mathrm{pH}$ raising from 7 to about 9.0, followed by addition of $\mathrm{Al}$ salt that brought final $\mathrm{pH}$ to 7.5; duration $5 \mathrm{~h}$.

Exp-3: simultaneous adding of $\mathrm{Al}$ salt and $\mathrm{NaOH}$ pellets (calculated by PHREEQC simulation) in order to keep $\mathrm{pH}$ about constant at the starting value of 7; however, $\mathrm{pH}$ lowering to about 4.2 was observed due to faster dissolution of $\mathrm{Al}$ salt with respect to $\mathrm{NaOH}$ pellets; final $\mathrm{pH}$ of 8.3 was obtained after complete dissolution of $\mathrm{NaOH}$ pellets; duration 5 h.

Exp-4: only addition of $\mathrm{Al}$ salt, causing $\mathrm{pH}$ lowering from 7 to about 4.2 , in order to identify the type of precipitate forming at acidic $\mathrm{pH}$ and assess its metal removal capacity to be compared to that of the precipitates recovered at near-neutral final conditions of Exp-1 to 3; duration $5 \mathrm{~h}$.

Exp-5: like Exp-1 but longer duration, $24 \mathrm{~h}$ after addition of $\mathrm{Al}$ salt and other $24 \mathrm{~h}$ after dropwise addition of $0.5 \mathrm{M} \mathrm{NaOH}$, in order to assess if the potential formation of a more crystalline precipitate may affect the metal removal efficiency; duration $48 \mathrm{~h}$.

A further experiment was conducted without analysing the solutions but with the only scope to collect the precipitates at different $\mathrm{pH}$ values (4.2, 6.0 and 8.5 ) to be analysed by X-ray absorption spectroscopy (XAS).

At the end of each laboratory experiment, water was filtered through $0.4 \mu \mathrm{m}$ membrane and different aliquots were prepared for chemical analyses by ICP-OES, ICP-MS and IC as described in section 3.1.

\subsection{Analysis of solids formed in the experiments}

At the end of each experiment, the precipitate was recovered by filtration with a vacuum pump system, rinsed with abundant deionised water, dried at room temperature and later ground in an agate mortar. Mineralogical analysis by powder X-ray diffraction (XRD) was performed using an X'pert Pro diffractometer (Panalytical) with $\theta-\theta$ geometry, Cu- $\mathrm{K}_{\alpha 1}$ wavelength radiation $(\lambda=1.54060 \AA)$ and X'Celerator detector, operating at $40 \mathrm{kV}$ and $40 \mathrm{~mA}$. XRD patterns were collected from 5 to $80^{\circ} 2 \theta$ with a step size of $0.02{ }^{\circ} 2 \theta$.

Environmental scanning electron microscopy with an energy dispersive X-ray system (ESEM-EDX, FEI Quanta 200) operating under high vacuum conditions $\left(10^{-6}-10^{-7}\right.$ torr $)$ at $20 \mathrm{kV}$, spot size 6 , and work distance of about $10 \mathrm{~mm}$, was used to acquire information on the precipitate from Exp-4.

High resolution transmission electron microscope (HRTEM) investigations were performed at the Department of Earth and Geoenvironmental Sciences of University of Bari (Italy) with a Jeol JEM 2010 operating at $200 \mathrm{kV}$, with $\mathrm{LaB}_{6}$ source, nominal point resolution of $2.0 \AA$, spherical aberration of $0.5 \mathrm{~mm}$. Images were recorded with a Gatan US 1000 CCD camera. Microanalyses were performed using an Oxford LINK energy dispersive X-ray spectrometer (EDX) with a Si(Li) detector and ultra-thin window. The samples were powdered and ultrasonically dispersed in octane. A few drops of the suspension were dispersed on Nickel grids with holey carbon film. A Jeol single tilt specimen holder was used.

The chemical environment of $\mathrm{Zn}$ in precipitates at different $\mathrm{pH}$ values was investigated by XAS at the Zn K-edge $(9.659 \mathrm{eV})$ at the XAFS (X-ray absorption fine structure) beamline, ELETTRA, Trieste, Italy (Di Cicco et al., 2009). In addition to the precipitates, synthetic ${\mathrm{ZnAl}-\mathrm{SO}_{4}}$ $\mathrm{LDH}\left[\mathrm{Zn}_{0.75} \mathrm{Al}_{0.25}(\mathrm{OH})_{2}\left(\mathrm{SO}_{4}\right)_{0.125} \cdot \mathrm{mH}_{2} \mathrm{O}\right]$ was analysed as reference compound. $\mathrm{ZnAl}-\mathrm{SO}_{4} \mathrm{LDH}$ was synthesized according to Ardau et al. (2012). Samples were prepared in form of self-supported pellets by mixing sample powders and polyvinyl pyrrolidone (PVP), then pressing at $5 \mathrm{kbar}$ for few minutes. XAS spectra were measured in transmission geometry keeping the sample at liquid nitrogen (TLN $~ 80 \mathrm{~K}$ ) in order to minimize the thermal disorder effect on the XAS structural signal. XAS data normalization, the extraction of the structural EXAFS (extended $\mathrm{X}$-ray absorption fine structure) signal $\chi(\mathrm{k})$ and the EXAFS data refinement were performed by standard procedures (Rehr and Albers, 2000) using the ESTRA and FITEXA code, respectively, as described by

Table 1

Typical chemical composition of the "Red Muds" drainage water as determined immediately after the field sampling.

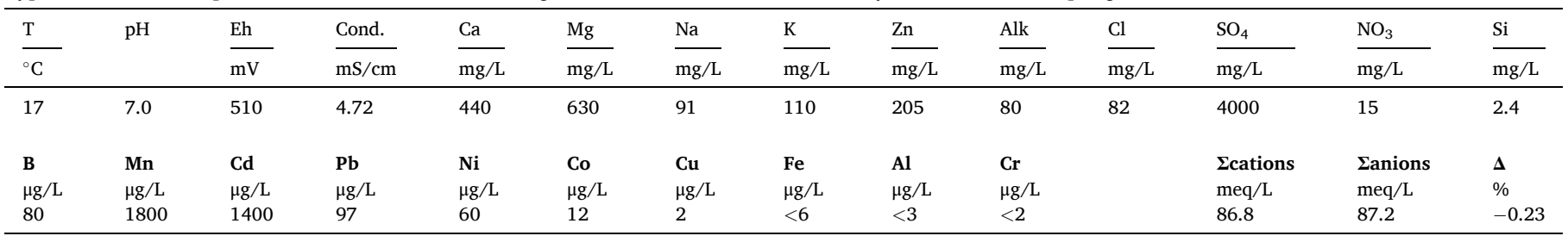

Alk: alkalinity expressed as $\mathrm{HCO}_{3}^{-} ; \Delta$ : charge balance calculated as 100 ( $\Sigma$ cations $-\Sigma$ anions $) /(\Sigma$ cations $+\Sigma$ anions $)$. 
Meneghini et al. (2012).

Chemical analysis of solid precipitates was performed by ICP-OES and ICP-MS after dissolving about $0.1 \mathrm{~g}$ of each sample with $3 \mathrm{~mL}$ of concentrated $\mathrm{HNO}_{3}$ and bringing to $50 \mathrm{~mL}$ final volume with high purity deionised water.

\section{Results}

\subsection{Drainage composition after the metal removal experiments}

The "Red Muds" drainage water used for the experiments is characterized by neutral $\mathrm{pH}$ (7.0), mildly oxidising redox potential (Eh = $510 \mathrm{mV})$, high conductivity $(4.72 \mathrm{mS} / \mathrm{cm})$ and high levels of sulfate (4000 mg/L), Mg (630 mg/L), Ca (440 mg/L), Zn (205 mg/L) and other divalent metals (1800 $\mu \mathrm{g} / \mathrm{L}$ Mn, $1400 \mu \mathrm{g} / \mathrm{L} \mathrm{Cd}, 97 \mu \mathrm{g} / \mathrm{L} \mathrm{Pb}, 60 \mu \mathrm{g} / \mathrm{L} \mathrm{Ni})$, but low concentrations of trivalent metals such as $\mathrm{Fe}^{3+}(<6 \mu \mathrm{g} / \mathrm{L})$ and $\mathrm{Al}^{3+}(<3 \mu \mathrm{g} / \mathrm{L})$ (Table 1$)$.

In Exp-1, 3 and 5, flocculation immediately started as $\mathrm{pH}$ lowered to 4.2 as a consequence of $\mathrm{Al}$ salt addition, and continued during $\mathrm{pH}$ raising to 8.3. In Exp-2, flocculation immediately started when the $\mathrm{Al}$ salt was added to the solution at $\mathrm{pH} 9.0$, and precipitation still occurred until $\mathrm{pH}$ value stabilized at 7.5. In Exp-4, flocculation immediately started as $\mathrm{pH}$ lowered to 4.2 as a consequence of $\mathrm{Al}$ salt addition, and $\mathrm{pH}$ was acidic throughout the experiment.

Final waters of Exp-1, 3 and 5 showed to have undergone similar high removal of $\mathrm{Zn}$ (99-100\%), $\mathrm{Pb}$ (92-96\%) and $\mathrm{Ni}$ (97-99\%), whereas Mn removal was decreasing from Exp-5 (98\%) to Exp-1 (86\%) and even further down to Exp-3 (46\%). A similar decreasing trend was observed for Cd removal but with appreciably lower percentages and gaps among them (40\% Exp-5, 37\% Exp-1, 33\% Exp-3) (Supplementary Table S1; Fig. 1).

Final water of Exp-2 showed to have undergone moderate removal of $\mathrm{Zn}(62 \%), \mathrm{Pb}(64 \%)$ and $\mathrm{Mn}$ (43\%), and almost no removal of Cd (1\%), whereas Ni removal was still high (88\%) (Supplementary Table S1; Fig. 1).

Final water of Exp-4 showed to have undergone very low metal removal (0-3\%) (Supplementary Table S1; Fig. 1).

Aluminium added to the drainage water was not detected in solution after the experiments, indicating a complete precipitation, with the exception of Exp-4 ( $23 \mu \mathrm{g} / \mathrm{L}$ of residual dissolved $\mathrm{Al}$ ).

\subsection{XRD and chemical analysis of solids}

From Exp-1, 3 and 5 a yellowish precipitate was recovered, and XRD analysis showed that poor-crystalline LDHs with a crystal structure similar to glaucocerinite $\left(\mathrm{Zn}_{1-\mathrm{x}} \mathrm{Al}_{\mathrm{x}}\right)(\mathrm{OH})_{2}\left(\mathrm{SO}_{4}\right)_{\mathrm{x} / 2} \cdot \mathrm{mH}_{2} \mathrm{O}(\mathrm{x}<0.5, \mathrm{~m}>$ $3 \times / 2$, Crystal System: Hexagonal) had formed (Witzke and Raade, 2000; Ardau et al., 2011) (Fig. 2a). From Exp-2 a white precipitate was recovered, and XRD analysis showed that a more crystalline LDH, structurally similar to the previous ones, had formed (Fig. 2b). Natural glaucocerinite may contain some $\mathrm{Cu}^{2+}$ replacing $\mathrm{Zn}^{2+}$ that gives the mineral a greenish-blue colour, but this is not our case because the parent solution had very low dissolved $\mathrm{Cu}^{2+}(2 \mu \mathrm{g} / \mathrm{L}$; Table 1$)$, and therefore the phases precipitated from Exp-1, 2, 3 and 5 can be defined as Cu-lacking glaucocerinite. From Exp-4 a white precipitate was recovered, and XRD analysis showed that a quasi-amorphous phase had formed (Fig. 2c).

The chemical composition of precipitates has allowed to calculate the stoichiometric formula of each phase (Table 2). The charge balance was $<|5| \%$ for all precipitates, indicating a high analytical goodness. The $\mathrm{M}^{2+} / \mathrm{M}^{3+}$ molar ratio of LDHs was close to 3 (as expected), except for the LDH precipitated from Exp-3 that showed a value closer to 4 due to a deficit of $\mathrm{Al}$ in the phase. The amount of $\mathrm{Mg}$ entering the LDHs structure in partial substitution of $\mathrm{Zn}$ was quite variable, with a $\mathrm{Zn} / \mathrm{Mg}$ molar ratio ranging from 1.52 (Exp-5) to 7.78 (Exp-3). No significant amounts of Ca were found in the precipitated LDHs, probably due to its notably higher ionic size (1.00 ̊ in octahedral coordination) with respect to $\mathrm{Zn}$ and $\mathrm{Mg}$ ( 0.74 and $0.72 \AA$, respectively), and its low propensity to be adsorbed. For these reasons, Ca was not included in the stoichiometric formulas reported in Table 2. With regard to the quasi-amorphous phase precipitated from Exp-4, it was a hydrated hydroxysulfate of Al, probably a poorly crystalline hydrobasaluminite $\mathrm{Al}_{4}\left(\mathrm{SO}_{4}\right)(\mathrm{OH})_{10} \cdot 12-36 \mathrm{H}_{2} \mathrm{O}$ (Sanchez-España and Reyes, 2019) that is a common precursor of felsöbányaite $\mathrm{Al}_{4}\left(\mathrm{SO}_{4}\right)(\mathrm{OH})_{10} \cdot 4 \mathrm{H}_{2} \mathrm{O}$.

\subsection{HRTEM and ESEM analyses of solids}

HRTEM analyses have highlighted the polycrystalline feature of precipitates from Exp-1, 2, 3 and 5. Among them, the precipitate from Exp-2 confirmed to be the most crystalline one (Fig. 3). Also the quasiamorphous feature of precipitate from Exp-4 was confirmed. Actually, the Bright Field (BF) image showed globular particles of about $250 \mathrm{~nm}$ in diameter and a typical Selected Area Electron Diffraction (SAED) of an amorphous material (Fig. 4a). Qualitative and semi-quantitative HRTEM microanalyses confirmed the chemical composition reported in Table 2. ESEM analysis of precipitate from Exp-4 has highlighted a different chemical composition of the brighter portion of the phase compared to the darker one, as visible from the back-scattered electron image and EDX spectra (Fig. 4b-d), which can be interpreted as the effect of a process of adsorption or surface precipitation of $\mathrm{Zn}^{2+}$ onto the quasi-amorphous Al-hydroxysulfate.

\subsection{XAS analysis of solids}

Fig. 5 shows Zn XANES (X-ray absorption near edge structure) Kedge spectra collected on precipitates formed at $\mathrm{pH} \mathrm{4.2,6}$ and 8.5, compared to the reference compound ZnAl LDH. The Zn XANES features of the " $\mathrm{pH} 4.2$ " precipitate are quite different from those of the reference compound. Specifically, the XANES features labelled as A and $\mathrm{A}^{\mathrm{I}}$ in the "pH 4.2" spectrum are absent in the ZnAl LDH spectrum, and the XANES features labelled as $\mathrm{B}^{\mathrm{I}}$ and $\mathrm{B}^{\mathrm{IV}}$ in the reference compound spectrum are no evident in the " $\mathrm{pH} 4.2$ " spectrum. In spectra of precipitates formed at pH 6 and 8.5, we can observe more analogies with the reference compound (labels $\mathrm{B}, \mathrm{B}^{\mathrm{I}}, \mathrm{B}^{\mathrm{II}}, \mathrm{B}^{\mathrm{III}}$ and $\mathrm{B}^{\mathrm{IV}}$ ) rather than with the " $\mathrm{pH} 4.2$ " precipitate, probably suggesting the occurrence of $\mathrm{Zn}$ in a coordination environment similar to that of the $\mathrm{ZnAl} \mathrm{LDH}$ phase.

The $\mathrm{k}^{2}$-weighted $\mathrm{Zn}$ EXAFS spectra $\mathrm{k}^{2} \chi(\mathrm{k})$ of the precipitates at different $\mathrm{pH}$ values and the reference compound are shown in Fig. 6, along with the best fit curves and the Fourier transform moduli (FT). A look at the EXAFS spectra of the " $\mathrm{pH} 4.2$ " precipitate, in comparison with the reference compound $\mathrm{ZnAl} \mathrm{LDH}$, confirms the differences among their $\mathrm{Zn}$ local structures. In particular, we can observe that, compared with the reference compound, the " $\mathrm{pH} 4.2$ " spectrum presents weaker structural features, pointing out a more disordered nature of the $\mathrm{Zn}$ chemical environment in this precipitate. In spectra of precipitates formed at $\mathrm{pH} 6$ and 8.5 the EXAFS region becomes more pronounced and the characteristic oscillation pattern in the $\chi$ spectra at $7-8 \AA^{-1}$ of LDH phases starts to appear (Starcher et al., 2017). This "beat" pattern is indicative of the brucite-like layers of an LDH structure (Scheinost and Sparks, 2000), and is well evident in the reference compound spectrum (Fig. 6).

The quantitative results for the reference compound and the precipitates at different $\mathrm{pH}$ values obtained from EXAFS data refinement are reported in Supplementary Table S2. The structural results of $\mathrm{ZnAl}$ LDH are in agreement with the available literature data (Downs and Hall-Wallace, 2003; Li et al., 2012). In the analysis of the reference compound we fixed the coordination number $(\mathrm{CN})$ of the first shell to the value given from the crystallographic model. Fitting results (Supplementary Table S2) indicate that $\mathrm{Zn}$ is present in an octahedral environment with $6 \mathrm{O}$ atoms at an interatomic distance of $2.09 \AA$ in the first shell. The next neighbour shells are $\mathrm{ZnAl}$ around $3.06 \AA$ (CN about 2 ), and ZnZn around $3.10 \AA$ (CN about 3). The Zn EXAFS spectrum of "pH 

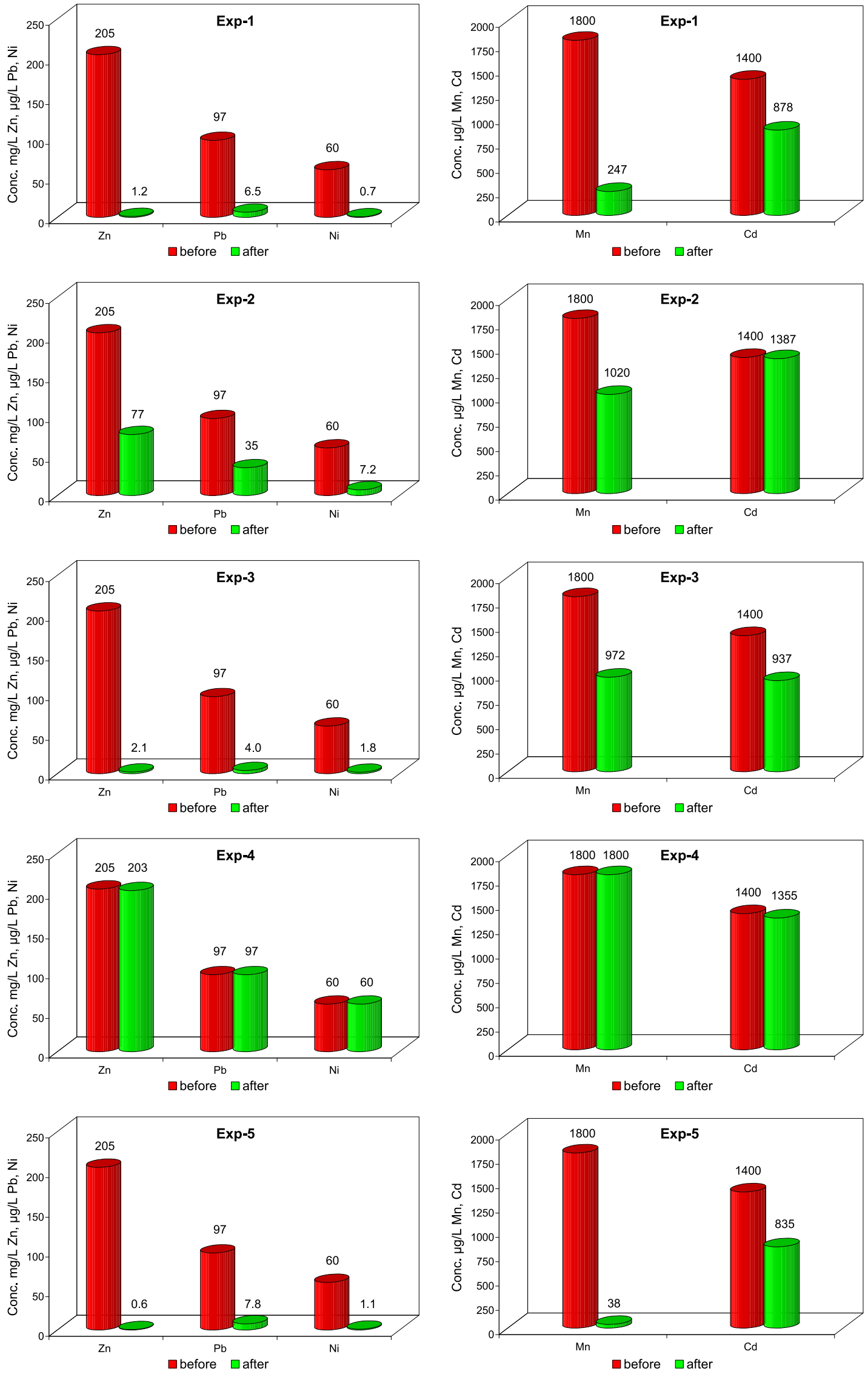

Fig. 1. Bar charts showing the dissolved concentrations of $\mathrm{Zn}, \mathrm{Pb}, \mathrm{Ni}, \mathrm{Mn}$ and $\mathrm{Cd}$ before and after each removal experiment. 

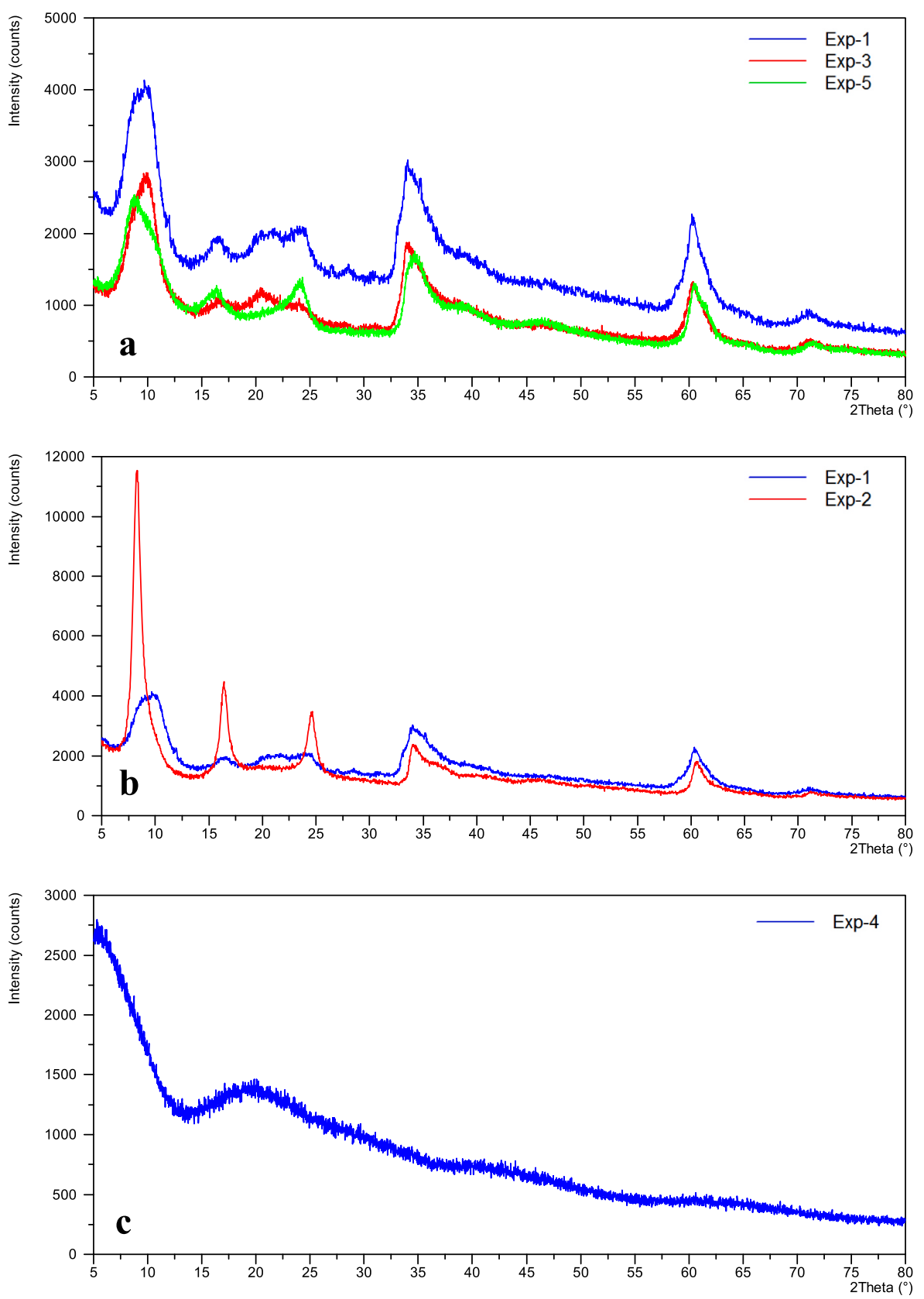

Fig. 2. XRD patterns. a) Precipitates from Exp-1, Exp-3 and Exp-5 (low-crystalline LDHs). b) Precipitate from Exp-2 (more crystalline LDH) compared to that from Exp-1 (low-crystalline LDH). c) Precipitate from Exp-4 (quasi-amorphous Al-hydroxysulfate).

4.2" precipitate (Supplementary Table S2; Fig. 6) can best be fitted with a first $\mathrm{ZnO}$ shell with $\mathrm{CN}=4$ at a distance of $1.97 \AA$ and a second $\mathrm{ZnAl}$ shell $(\mathrm{CN}=1)$ at $3.09 \AA$, suggesting the occurrence of an inner-sphere sorption complex (Trainor et al., 2000; Roberts et al., 2003; Li et al., 2012). Fitting of precipitates formed at $\mathrm{pH} 6$ and $\mathrm{pH} 8.5$ was performed fixing the $\mathrm{CN}$ of the first shell to the value of the reference compound due to the similarities observed in the XANES (Fig. 5) and EXAFS (Fig. 6) regions. The results show that $\mathrm{Zn}$ is bound to $\mathrm{O}$ at an interatomic distance of $2.06 \AA$ in the first shell, and to $\mathrm{Al}$ ( $\mathrm{CN}$ in the range of 0.5-0.8) at about $3.07 \AA$, and to $\mathrm{Zn}(\mathrm{CN}$ in the range of $0.8-1.2)$ at about $3.14 \AA$ (Supplementary Table S2). These findings suggest that at $\mathrm{pH} 4.2$ the inner-sphere adsorption of $\mathrm{Zn}$ on the quasi-amorphous Al-hydroxysulfate dominates, and as $\mathrm{pH}$ increases ( $\mathrm{pH} 6$ and 8.5) the major phase becomes a $\mathrm{ZnAl} \mathrm{LDH}$, probably because of a gradual incorporation of $\mathrm{Zn}$ in the structure of the quasi-amorphous Al-hydroxysulfate that progressively transforms into an LDH structure.

\section{Discussion}

All metal removal experiments carried out using a near-neutral drainage from the "Red Muds" impoundment showed a prompt flocculation occurring both at acidic pH (Exp-1, 3, 4 and 5) and at alkaline $\mathrm{pH}$ (Exp-2). With the exception of Exp-4 that was deliberately conducted with a single $\mathrm{pH}$ step (from 7.0 to 4.2 ), the other experiments were characterized by a two-step pH control method: from 7.0 to 4.2 (1st step) and from 4.2 to 8.3 (2nd step) for Exp-1, 3 and 5; from 7.0 to 9.0 (1st step) and from 9.0 to 7.5 (2nd step) for Exp-2.

The metal removal efficiency (Supplementary Table S1; Fig. 1) is clearly affected by two main factors: 1) the two pH steps; 2) the direction of $\mathrm{pH}$ variation within each step. In particular, the highest removal of metals is obtained when the $1 \mathrm{st} \mathrm{pH}$ step goes towards acidic conditions, as a consequence of $\mathrm{Al}$ salt addition, and precipitation of a quasiamorphous hydrated hydroxysulfate of $\mathrm{Al}$ occurs. However, this 1st 
Table 2

Stoichiometric formulas of synthetic $\mathrm{ZnAl}-\mathrm{SO}_{4} \mathrm{LDH}$ used as reference compound, $(\mathrm{Zn}+\mathrm{Mg}) \mathrm{Al}-\mathrm{SO}_{4} \mathrm{LDH}$ phases collected at the end of Exp-1, 2, 3 and 5, and quasi-amorphous Al-hydroxysulfate from Exp-4.

\begin{tabular}{|c|c|c|c|c|}
\hline & Type of phase & Stoichiometric formula & $\begin{array}{l}(\mathrm{Zn}+ \\
\mathrm{Mg}) / \mathrm{Al} \\
\text { molar } \\
\text { ratio }\end{array}$ & $\begin{array}{l}\Delta \\
\%\end{array}$ \\
\hline Ref. compound & synthetic LDH & $\begin{array}{l}\mathrm{Zn}_{0.75} \mathrm{Al}_{0.25}(\mathrm{OH})_{2} \\
\left(\mathrm{SO}_{4}\right)_{0.125} \cdot \mathrm{mH}_{2} \mathrm{O}\end{array}$ & 3.0 & 0 \\
\hline Exp-1 & $\begin{array}{l}\text { low-crystalline } \\
\text { LDH }\end{array}$ & $\begin{array}{l}\mathrm{Zn}_{0.49} \mathrm{Mg} \mathrm{O}_{0.24} \mathrm{Al}_{0.26} \\
(\mathrm{OH})_{2}\left(\mathrm{SO}_{4}\right)_{0.12} \cdot \mathrm{mH}_{2} \mathrm{O}\end{array}$ & 2.8 & 0 \\
\hline Exp-2 & $\begin{array}{l}\text { more crystalline } \\
\text { LDH }\end{array}$ & $\begin{array}{l}\mathrm{Zn}_{0.66} \mathrm{Mg}_{0.11} \mathrm{Al}_{0.23} \\
(\mathrm{OH})_{2}\left(\mathrm{SO}_{4}\right)_{0.08} \cdot \mathrm{mH}_{2} \mathrm{O}\end{array}$ & 3.3 & 3.2 \\
\hline Exp-3 & $\begin{array}{l}\text { low-crystalline } \\
\text { LDH }\end{array}$ & $\begin{array}{l}\mathrm{Zn}_{0.70} \mathrm{Mg}_{0.09} \mathrm{Al}_{0.21} \\
(\mathrm{OH})_{2}\left(\mathrm{SO}_{4}\right)_{0.12} \cdot \mathrm{mH}_{2} \mathrm{O}\end{array}$ & 3.8 & -1.3 \\
\hline Exp-5 & $\begin{array}{l}\text { low-crystalline } \\
\text { LDH }\end{array}$ & $\begin{array}{l}\mathrm{Zn}_{0.44} \mathrm{Mg}_{0.29} \mathrm{Al}_{0.27} \\
(\mathrm{OH})_{2}\left(\mathrm{SO}_{4}\right)_{0.11} \cdot \mathrm{mH}_{2} \mathrm{O}\end{array}$ & 2.7 & 2.2 \\
\hline Exp-4 & $\begin{array}{l}\text { quasi- } \\
\text { amorphous Al- } \\
\text { hydroxysulfate }\end{array}$ & $\begin{array}{l}\mathrm{Al}_{3.88}\left(\mathrm{SO}_{4}\right)_{1.08}(\mathrm{OH})_{10} \\
\mathrm{mH}_{2} \mathrm{O}\end{array}$ & - & -4.4 \\
\hline
\end{tabular}

$\Delta=100[(\Sigma$ positive charges $)-(\Sigma$ negative charges $)] / 0.5[(\Sigma$ positive charges $)$ $+(\Sigma$ negative charges $)]$.

acidic $\mathrm{pH}$ step does not remove metals (just 0-3\%) (Supplementary Table S1; Fig. 1) but it is essential in order that the 2nd $\mathrm{pH}$ step towards slightly alkaline conditions can be highly efficient in removing divalent metals. In fact, as clearly demonstrated by XRD and XAS analyses, the quasi-amorphous hydrated hydroxysulfate of $\mathrm{Al}$ gradually turns into an $\mathrm{LDH}$ incorporating $\mathrm{Zn}, \mathrm{Mg}$ and other metals.

Our results about the two-step $\mathrm{pH}$ mechanism of LDH formation are in accordance with the preliminary experiments of LDH synthesis at varying $\mathrm{pH}$ conducted by Seron and Delorme (2008). They synthesized a $\mathrm{MgAl} \mathrm{LDH}$ starting from $\mathrm{pH} 2.4$ up to $\mathrm{pH}$ 13.2, and observed an Al-rich phase firstly forming at low $\mathrm{pH}$ which tends to continuously incorporate $\mathrm{Mg}$ until $\mathrm{LDH}$ with the targeted $\mathrm{Mg} / \mathrm{Al}$ ratio is obtained at high $\mathrm{pH}$.

The fundamental role played by the quasi-amorphous hydrated hydroxysulfate of $\mathrm{Al}$ formed at acidic $\mathrm{pH}$ is also deductible from ESEMEDX analysis of Exp-4 precipitate (Fig. 4b-d), where Zn appears to be adsorbed or to form a surface precipitate in some portions (the brighter ones) of the quasi-amorphous Al-bearing phase. According to these observations, XAS analysis revealed that $\mathrm{Zn}$ is adsorbed on the surface of the quasi-amorphous hydrated hydroxysulfate of $\mathrm{Al}$ through an innersphere complex with $\mathrm{CN}=4$. Considering the concentrations of divalent metals in the "Red Muds" drainage (Table 1) and the type of LDH formed by induced precipitation (Table 2), the removal of $\mathrm{Zn}$ is certainly due to its entrance into the brucite-like sheets of $\mathrm{LDH}$ as main divalent cation in octahedral coordination, whereas the removal of other metals, which show dissolved concentrations of two orders of magnitude lower than $\mathrm{Zn}$ and $\mathrm{Mg}$ (Table 1), may be due to different mechanisms (Liang et al., 2013). According to the effective ionic radii (e.i.r.) in octahedral coordination (Shannon, 1976), $\mathrm{Ni}^{2+}$ (e.i.r. $=0.69 \AA$ ) and $\mathrm{Mn}^{2+}$ (e.i.r. = $0.67 \AA$ ) may replace $\mathrm{Zn}^{2+}$ (e.i.r. $=0.74 \AA$ ) and $\mathrm{Mg}$ (e.i.r. $=0.72 \AA$ ), having similar ionic radii, whereas $\mathrm{Cd}^{2+}$ (e.i.r. $=0.95 \AA$ ) and $\mathrm{Pb}^{2+}$ (e.i.r. $=1.19 \AA$ ) are considerably larger and thus adsorption on LDH surface might be more probable, although isomorphic substitution between $\mathrm{Zn}$ and $\mathrm{Cd}$ is very common in some minerals (e.g., sphalerite $\mathrm{ZnS}$ ). Zhao et al. (2011) demonstrated that $\mathrm{Pb}$ (II) is efficiently adsorbed $\left(\mathrm{q}_{\max }=66\right.$ $\mathrm{mg} / \mathrm{g}$ ) by $\mathrm{Mg}_{2} \mathrm{Al} \mathrm{LDH}$ in the $\mathrm{pH}$ range of 6.5-10. At a given $\mathrm{pH}$ value, the adsorption of a metal ion is generally influenced by its aqueous speciation and the coexistence of other ions that may compete for the binding sites. Given the compositional complexity of the "Red Muds" drainage, it is not possible to evaluate the reciprocal ionic interactions affecting metal adsorption. Finally, although less probable, we cannot rule out a removal mechanism for some metals by $\mathrm{LDH}$-surface catalyzed precipitation of their amorphous hydroxides.

Another evidence of the fundamental role played by the quasiamorphous hydrated hydroxysulfate of $\mathrm{Al}$ formed at acidic $\mathrm{pH}$ in triggering an efficient removal of metals is given by the results of Exp-2, where $\mathrm{pH}$ was always maintained in a neutral-alkaline range throughout the experiment. In that case, the removal efficiency of $\mathrm{LDH}$, directly precipitated via oversaturation under neutral-alkaline conditions, was significantly lower (Supplementary Table S1; Fig. 1) than that of LDH formed via gradual transformation of the quasi-amorphous hydrated hydroxysulfate of $\mathrm{Al}$ precipitated at acidic $\mathrm{pH}$. The lower removal efficiency of LDH from Exp-2 could be due to its higher crystallinity (Fig. 2b) that reduces the possibility of incorporating/adsorbing trace metals when compared to the LDH with lower crystallinity. However, the degree of LDH crystallinity does not seem to be influenced by the duration of the removal experiment but much more by the solution $\mathrm{pH}$ value reached during the experiment (Seron and Delorme, 2008). In fact, the degree of crystallinity is very similar for the LDHs formed in the Exp-1 and 5 (Fig. 2a), although the two experiments differ significantly in duration ( 5 and $48 \mathrm{~h}$, respectively), while maintaining the same $\mathrm{pH}$ variations (1st pH step from 7.0 to $4.2 ; 2$ nd pH step from 4.2 to 8.3) and the same metal removal efficiency (Supplementary Table S1; Fig. 1). On the contrary, the $\mathrm{LDH}$ from Exp-2 directly formed at higher $\mathrm{pH}$ values (1st $\mathrm{pH}$ step from 7.0 to $9.0 ; 2$ nd $\mathrm{pH}$ step from 9.0 to 7.5 ) that favour a better degree of crystallinity (Fig. 2b) and consequently a lower capacity of uptake metals from solution (Supplementary Table S1; Fig. 1). Therefore, the best procedure for obtaining the highest metal removal appears to be that followed in the Exp-1 and 5 (i.e., addition of Al salt that causes $\mathrm{pH}$ lowering from 7 to about 4.2, followed by dropwise addition of $0.5 \mathrm{M} \mathrm{NaOH}$ to bring final $\mathrm{pH}$ to 8.3). This procedure deserves to be developed and refined in future studies.

Due to its higher crystallinity, LDH from Exp-2 can be used to obtain crystallographic information. The hexagonal lattice parameters $a$ and $c$ of this phase can be calculated as follows: $a=2 \mathrm{~d}_{(110)}=3.06 \AA$ and $c=$ $3 \mathrm{~d}_{(003)}=32.38 \AA$, where $\mathrm{d}_{(110)}$ is the reflection at $60.382{ }^{\circ} 2 \theta$ and $\mathrm{d}_{(003)}$ is the basal reflection at $8.185^{\circ} 2 \theta$ (Fig. 2b). These lattice parameters are rather close to those of glaucocerinite ( $a=3.07 \AA, c=32.65 \AA$, PDF-2 reference code: 00-039-0338). The two rings at $1.53 \AA$ and $2.58-2.65$ $\AA$ visible in the SAED patterns of Exp-1, 2, 3 and 5 precipitates (Fig. 3) correspond to XRD effects at about 61 and $34^{\circ} 2 \theta$ (Fig. 2a-b) from the crystallographic planes (110) and (012), respectively; the Lattice Fringe with interplanar spacing of $10.79 \AA$ (Fig. 3b) can be attributed to the crystallographic plane (003) with XRD effect at about 8-9 ${ }^{\circ} 2 \theta$ (Fig. 2a-b).

\section{Conclusions}

The induced precipitation of LDH has been demonstrated to be an effective method to treat polluted near-neutral mining and metallurgical waste drainages characterized by a multiple divalent metal composition. The method is very simple and based on two $\mathrm{pH}$ steps that include the addition of a salt of $\mathrm{Al}$ (acidic $\mathrm{pH}$ step) and the use of a base (e.g., $\mathrm{NaOH}$ ) to restore the solution $\mathrm{pH}$ to a neutral or slightly alkaline value. The metal removal efficiency is generally very high (up to $100 \% \mathrm{Zn}, 98 \%$ $\mathrm{Mn}, 96 \% \mathrm{~Pb}, 99 \% \mathrm{Ni}, 40 \% \mathrm{Cd}$ ) and strongly favoured by the formation at low $\mathrm{pH}$ of a quasi-amorphous Al-bearing phase which tends to continuously incorporate metals while transforming into $\mathrm{LDH}$ as $\mathrm{pH}$ is increased. The great versatility of LDHs in uptaking different pollutants, both cations and anions, according to different mechanisms (i.e., precipitation, surface adsorption, surface precipitation, anion exchange), makes them very promising phases for the treatment of chemically complex wastewaters, such as circum-neutral metal and metalloid polluted mining and metallurgical waste drainages.

With regard to the overall costs of the treatment method, also including how to manage the metal-bearing LDH sludge generated in the process, at the current state of research we can only make some considerations. Although the sludge disposal often represents a disadvantage of active treatment systems, there are numerous cases of sludge recycling and/or metal recovery from the sludge (Kefeni et al., 2017; Calugaru et al., 2018). On the other hand, also many passive treatment 


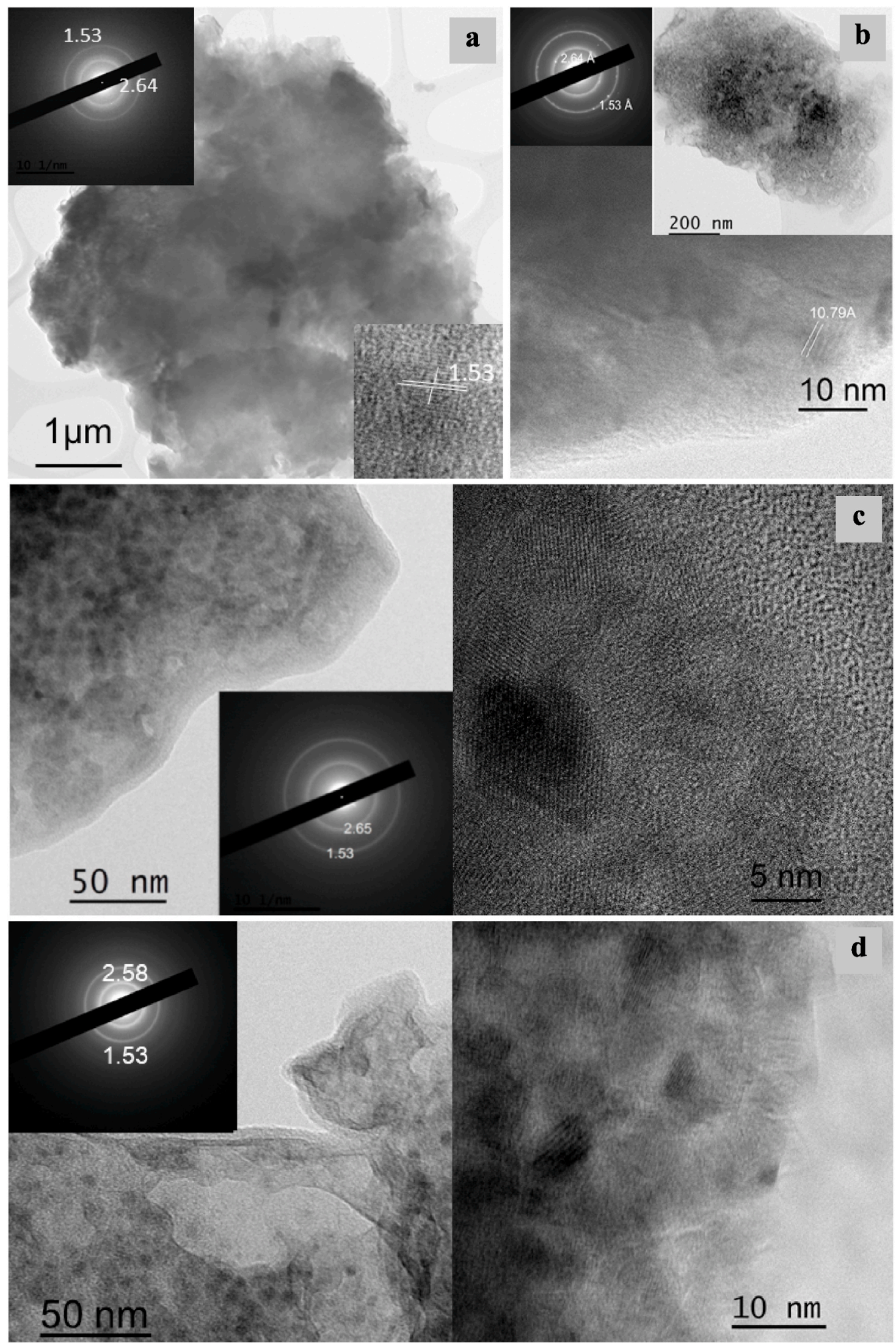

Fig. 3. HRTEM analyses. a) Exp-1 precipitate (low-crystalline LDH): BF image, related SAED pattern showing two weak rings at 1.53 and $2.64 \AA$ And LF showing an interplanar spacing of $1.53 \AA$. b) Exp-2 precipitate (more crystalline LDH): BF image, related SAED pattern showing two more outlined rings at 1.53 and $2.64 \AA$ with some spots, and LF image showing an interplanar spacing of 10.79 A. c) Exp-3 precipitate (low-crystalline LDH): BF image with related SAED pattern (on the left) showing two weak rings at 1.53 and $2.65 \AA$, and HRTEM image (on the right). d) Exp-5 precipitate (low-crystalline LDH): BF image with related SAED pattern (on the left) showing two weak rings at 1.53 and $2.58 \AA$, and LF image (on the right). 

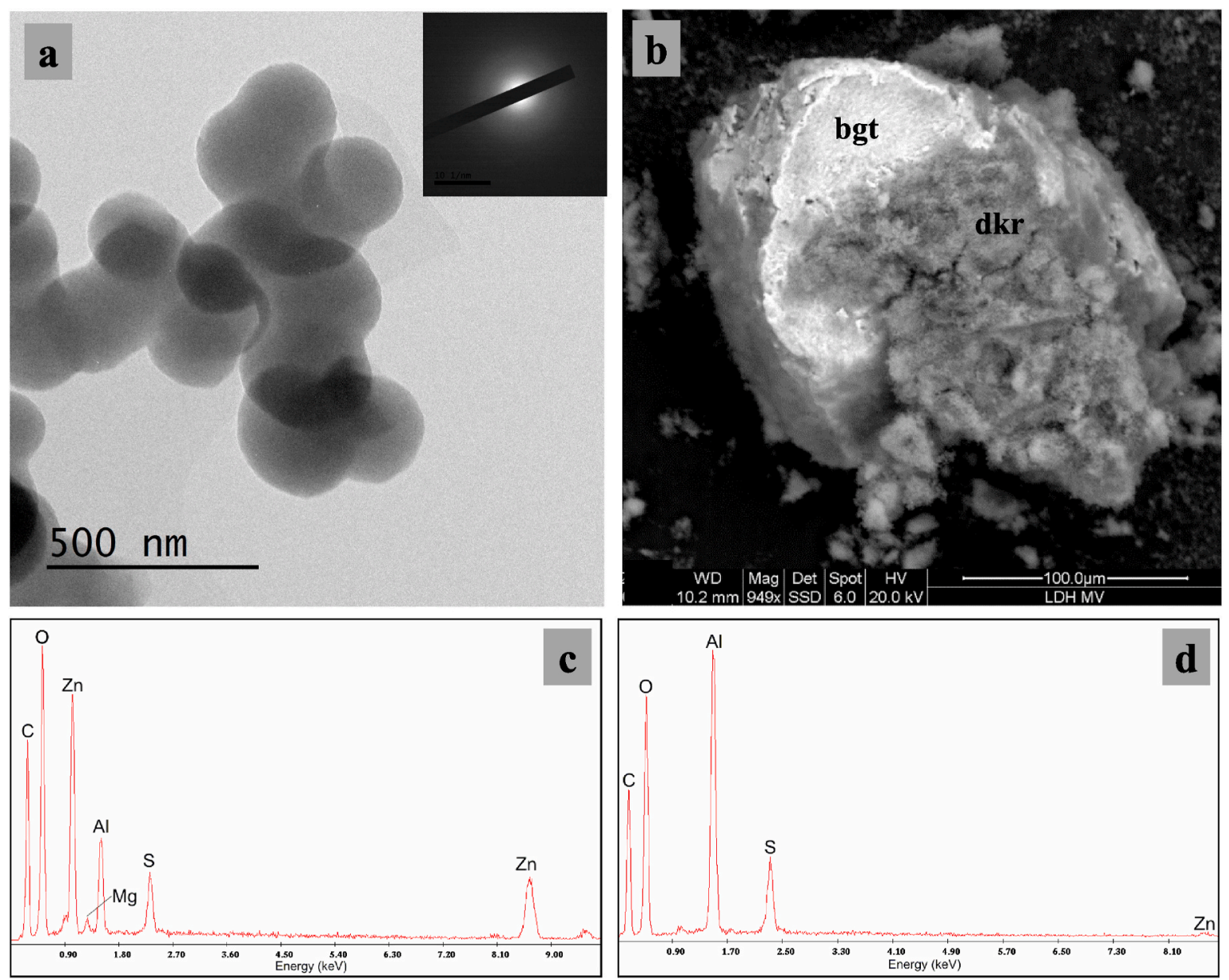

Fig. 4. HRTEM and ESEM analyses. a) HRTEM BF image of Exp-4 precipitate (quasi-amorphous Al-hydroxysulfate) and related SAED pattern, showing the amorphous feature of the phase. b) ESEM back-scattered electron image of Exp-4 precipitate. c) ESEM EDX spectrum of the brighter portion of Exp-4 precipitate marked as bgt in (b). d) ESEM EDX spectrum of the darker portion of Exp-4 precipitate marked as dkr in (b).

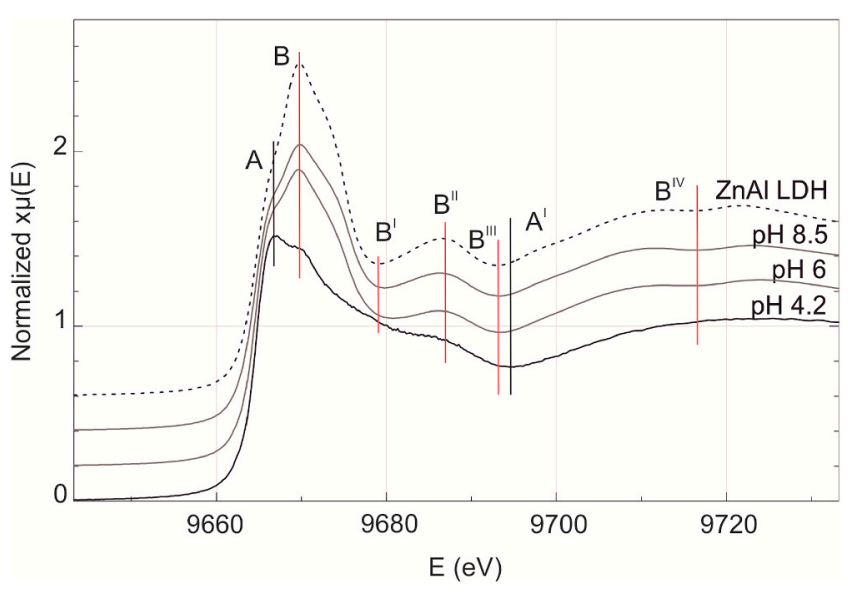

Fig. 5. XANES spectra at the $\mathrm{Zn} \mathrm{K-edge} \mathrm{of} \mathrm{the} \mathrm{precipitates} \mathrm{at} \mathrm{pH} 4.2$, $\mathrm{pH} 6$ and $\mathrm{pH}$ 8.5. Spectrum of the reference compound $\mathrm{ZnAl} \mathrm{LDH}$ is reported for comparison. Spectra are vertically shifted for clarity.

systems generate sludge, although it is generally denser than that generated in active systems and thus more easily and less frequently to be handled (Skousen et al., 2017). In our case, the sludge generated consists of a sulfate LDH that might be calcined to obtain a mixed metal oxide for metal recovery or for reuse in uptaking anionic contaminants from circum-neutral polluted solutions through the so-called "memory effect" (Dore and Frau, 2018, 2019; Dore et al., 2019). As an alternative, the sulfate LDH sludge might be used as it is, taking advantage of its high anion exchange capacity between sulfate and toxic oxyanions of some metalloids, such as those of $\mathrm{As}(\mathrm{V})$ and $\mathrm{Sb}(\mathrm{V})$, dissolved in neutral or slightly alkaline polluted solutions (Ardau et al., 2011, 2013, 2016).

Further studies involving the refinement and application of the method are necessary in order to carry out an overall cost analysis.

\section{Funding}

The research was funded through a doctoral scholarship issued by the Consorzio AUSI (Iglesias, Sardinia, Italy) in favour of Roberta Atzori. The research was also partially financed with funds from the Fondazione di Sardegna (Cagliari, Italy) for research projects of the University of Cagliari, Italy (FdS-2018 project - CUP F74I19000960007).

\section{Declaration of competing interest}

The authors declare that they have no known competing financial interests or personal relationships that could have appeared to influence the work reported in this paper.

\section{CRediT authorship contribution statement}

Franco Frau: Conceptualization, Methodology, Writing - original draft, Writing - review \& editing, Supervision. Roberta Atzori: Validation, Investigation, Resources, Data curation. Carla Ardau: 

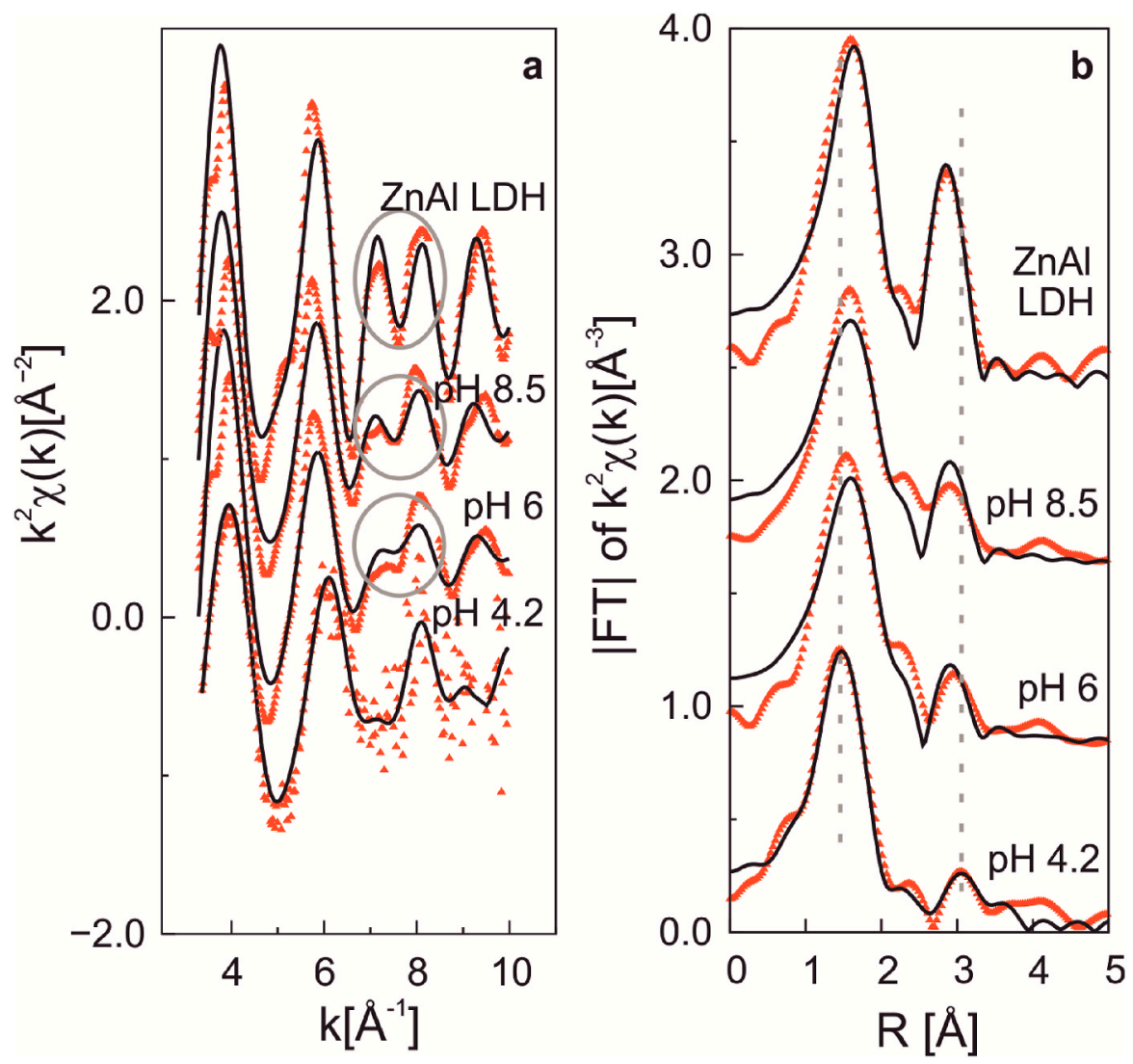

Fig. 6. a) Experimental data (red triangles) and best fits (full lines) of the precipitates at pH 4.2, pH 6 and pH 8.5, compared with data of the reference compound $\mathrm{ZnAl} \mathrm{LDH.} \mathrm{Grey} \mathrm{ovals} \mathrm{indicate} \mathrm{the} \mathrm{diagnostic} \mathrm{LDH} \mathrm{beat} \mathrm{pattern} \mathrm{between} \mathrm{k} 7$ and $8 \AA^{-1}$. b) Fourier transforms of EXAFS spectra. (For interpretation of the references to colour in this figure legend, the reader is referred to the Web version of this article.)

Validation, Investigation, Resources, Data curation. Daniela Medas: Validation, Investigation, Resources, Data curation. Francesca Podda: Validation, Investigation, Resources, Data curation. Elisabetta Dore: Validation, Investigation, Resources, Data curation. Alfredo Idini: Validation, Investigation, Resources, Data curation. Gioacchino Tempesta: Validation, Investigation, Resources, Data curation. Giovanna Agrosì: Validation, Investigation, Resources, Data curation.

\section{Acknowledgements}

The authors are grateful to "Potenziamento Strutturale PONa300369 SISTEMA, University of Bari A. Moro”, Italy, for HRTEM analyses. We acknowledge the Scientists from the XAFS beamline (Elettra Sincrotrone, Trieste, Italy), and Prof. Carlo Meneghini and Prof. Giovanni De Giudici for their support during XAS measurements (beamtime 20167045). The authors also acknowledge the CeSAR (Centro Servizi d'Ateneo per la Ricerca) of the University of Cagliari, Italy, for ESEM analysis. We thank Javier Sánchez-España and an anonymous reviewer for their careful reading of our manuscript and their insightful comments and suggestions.

\section{Appendix A. Supplementary data}

Supplementary data to this article can be found online at https://doi. org/10.1016/j.jenvman.2020.111043.

\section{References}

Ardau, C., Frau, F., Dore, E., Lattanzi, P., 2012. Molybdate sorption by Zn-Al sulphate layered double hydroxides. Appl. Clay Sci. 65-66, 128-133.
Ardau, C., Frau, F., Lattanzi, P., 2013. New data on arsenic sorption properties of Zn-Al sulphate layered double hydroxides: influence of competition with other anions. Appl. Clay Sci. 80-81, 1-9.

Ardau, C., Frau, F., Lattanzi, P., 2016. Antimony removal from aqueous solutions by the use of Zn-Al sulphate layered double hydroxide. Water Air Soil Pollut. 227 (9), 344.

Ardau, C., Frau, F., Ricci, P.C., Lattanzi, P., 2011. Sulphate-arsenate exchange properties of $\mathrm{Zn}-\mathrm{Al}$ layered double hydroxides: preliminary data. Period. Mineral. 80 (2), 339-349.

Banks, D., Younger, P.L., Arnesen, R.-T., Iversen, E.R., Banks, S.D., 1997. Mine-water chemistry: the good, the bad and the ugly. Environ. Geol. 32 (3), 157-174.

Biddau, R., Fanfani, L., Lattanzi, P., Zuddas, P., 2001. Acid mine drainage prediction by acid-base accounting tests in abandoned mine tailings from Sardinia. In: Proceedings of the $10^{\text {th }}$ International Symposium on Water-Rock Interaction (WRI-10), July 1015, 2001, Villasimius, Italy, vol. 2, ISBN 9026518358, pp. 1185-1188. July 10-15.

Boni, M., 1994. Ores in southwestern Sardinia. Memorie Descrittive Carta Geologica d'Italia XLVIII, 155-184.

Boni, M., Costabile, S., De Vivo, B., Gasparrini, M., 1999. Potential environmental hazard in the mining district of southern Iglesiente (SW Sardinia, Italy). J. Geochem. Explor. $67,417-430$.

Buosi, M., Contini, E., Enne, R., Farci, A., Garbarino, C., Naitza, S., Tocco, S., 2001 Contributo alla conoscenza dei materiali delle discariche della miniera di Monteponi: i ‘Fanghi Rossi' dell'elettrolisi. Caratterizzazione fisico-geotecnica e chimico-mineralogica. Definizione del potenziale inquinante e proposte per possibili interventi. Atti Associazione Mineraria Sarda 99, 49-92 (in Italian).

Calugaru, I.L., Neculita, C.M., Genty, T., Zagury, G.J., 2018. Metals and metalloids treatment in contaminated neutral effluents using modified materials. J. Environ. Manag. 212, 142-159.

Carriazo, D., del Arco, M., Martín, C., Rives, V.A., 2007. A comparative study between chloride and calcined carbonate hydrotalcites as adsorbent for $\mathrm{Cr}(\mathrm{VI})$. Appl. Clay Sci. $37,231-239$.

Cavani, F., Trifirò, F., Vaccari, A., 1991. Hydrotalcite-type anionic clays: preparation, properties and applications. Catal. Today 11, 173-301.

Cidu, R., Biddau, R., Spano, T., 2005. Temporal variations in water chemistry at abandoned underground mines hosted in a carbonate environment. Mine Water Environ. 24, 77-87.

Cidu, R., Fanfani, L., 2002. Overview of the environmental geochemistry of mining districts in southwestern Sardinia, Italy. Geochem.-Explor. Environ. Anal. 2, 243-251.

Contini, E., Garbarino, C., Tocco, S., 1999. Inertizzazione dei "fanghi rossi" delle discariche di Monteponi mediante processo termico. Risultati e caratteristiche dei 
prodotti di risulta. Atti della Facoltà di Ingegneria, Università di Cagliari 42, 129-135 (in Italian).

De Giudici, G., Medas, D., Cidu, R., Lattanzi, P., Podda, F., Frau, F., Rigonat, N., Pusceddu, C., Da Pelo, S., Onnis, P., Marras, P.A., Wanty, R.B., Kimball, B., 2018. Application of hydrologic-tracer techniques to the Casargiu adit and Rio Irvi (SWSardinia, Italy): using enhanced natural attenuation to reduce extreme metal loads. Appl. Geochem. 96, 42-54.

De Giudici, G., Pusceddu, C., Medas, D., Meneghini, C., Gianoncelli, A., Rimondi, V., Podda, F., Cidu, R., Lattanzi, P., Wanty, R.B., Kimball, B.A., 2017. The role of natural biogeochemical barriers in limiting metal loading to a stream affected by mine drainage. Appl. Geochem. 76, 124-135.

Di Cicco, A., Aquilanti, G., Minicucci, M., Principi, E., Novello, N., Cognigni, A., Olivi, L. 2009. Novel XAFS capabilities at ELETTRA synchrotron light source. J. Phys.: Conf. Ser. 190, 012043.

Dore, E., Frau, F., 2018. Antimonate uptake by calcined and uncalcined layered double hydroxides: effect of cationic composition and $\mathrm{M}^{2+} / \mathrm{M}^{3+}$ molar ratio. Environ. Sci. Pollut. Res. 25, 916-929.

Dore, E., Frau, F., 2019. Calcined and uncalcined carbonate layered double hydroxides for possible water defluoridation in rural communities of the East African Rift Valley. J. Water Process. Eng. 31, 100855.

Dore, E., Frau, F., Cidu, R., 2019. Antimonate removal from polluted mining water by calcined layered double hydroxides. Crystals 9, 410.

Downs, R.T., Hall-Wallace, M., 2003. The American mineralogist crystal structure database. Am. Miner. 88, 247-250.

Frau, F., Addari, D., Atzei, D., Biddau, R., Cidu, R., Rossi, A., 2010. Influence of major anions on $\mathrm{As}(\mathrm{V})$ adsorption by synthetic 2-line ferrihydrite. Kinetic investigation and XPS study of the competitive effect of bicarbonate. Water Air Soil Pollut. 205, 25-41.

Frau, F., Ardau, C., 2004. Mineralogical controls on arsenic mobility in the Baccu Locci stream catchment (Sardinia, Italy) affected by past mining. Mineral. Mag. 68 (1), 15-30.

Frau, F., Biddau, R., Fanfani, L., 2008. Effect of major anions on arsenate desorption from ferrihydrite-bearing natural samples. Appl. Geochem. 23 (6), 1451-1466.

Frau, F., Cidu, R., Ardau, C., 2012. Short-term changes in water chemistry in the Baccu Locci stream (Sardinia, Italy) affected by past mining. Appl. Geochem. 27 (9), 1844-1853.

Frau, F., Medas, D., Da Pelo, S., Wanty, R.B., Cidu, R., 2015. Environmental effects on the aquatic system and metal discharge to the Mediterranean Sea from a near-neutral zinc-ferrous sulfate mine drainage. Water Air Soil Pollut. 226 (3), 55.

Goh, K.H., Lim, T.T., Dong, Z., 2008. Application of layered double hydroxides for removal of oxyanions: a review. Water Res. 42, 1343-1368.

Hu, X., Guo, X., He, M., Li, S., 2016. pH-dependent release characteristics of antimony and arsenic from typical antimony-bearing ores. J. Environ. Sci. 44, 171-179.

Iribar, V., 2004. Origin of neutral mine water in flooded underground mines: an appraisal using geochemical and hydrogeological methodologies. In: "Mine Water 2004 Process, Policy, and Progress", Proceedings of International Mine Water Association Symposium 2004, September 20-25, 2004. Newcastle upon Tyne, United Kingdom, ISBN 978-1-62276-985-8, pp. 260-274.

Johnson, D.B., Hallberg, K.B., 2005. Acid mine drainage remediation options: a review. Sci. Total Environ. 338, 3-14.

Kameda, T., Kondo, E., Yoshioka, T., 2015. Equilibrium and kinetics studies on As(V) and $\mathrm{Sb}(\mathrm{V})$ removal by $\mathrm{Fe}^{2+}$ doped $\mathrm{Mg}$-Al layered double hydroxides. J. Environ. Manag. 151, 303-309.

Kefeni, K.K., Msagati, T.A.M., Mamba, B.B., 2017. Acid mine drainage: prevention, treatment options, and resource recovery: a review. J. Clean. Prod. 151, 475-493.

Leuz, A.K., Mönch, H., Johnson, C.A., 2006. Sorption of Sb(III) and Sb(V) to goethite: influence on Sb(III) oxidation and mobilization. Environ. Sci. Technol. 40, 7277-7282.

Li, F., Duan, X., 2006. Applications of layered double hydroxides. In: Duan, X., Evans, D. G. (Eds.), Layered Double Hydroxides. Structure and Bonding, vol. 119. Springer, Berlin, Heidelberg.

Li, W., Livi, K.J.T., Xu, W., Siebecker, M.G., Wang, Y., Phillips, B.L., Sparks, D., 2012. Formation of crystalline $\mathrm{Zn}-\mathrm{Al}$ layered double hydroxide precipitates on $\gamma$-alumina: the role of mineral dissolution. Environ. Sci. Technol. 46, 11670-11677.

Liang, X., Zang, Y., Xu, Y., Tan, X., Hou, W., Wang, L., Sun, Y., 2013. Sorption of metal cations on layered double hydroxides. Colloid Surf. A-Physicochem. Eng. Asp. 433, $122-131$.

Lindsay, M.B.J., Condon, P.D., Jambor, J.L., Lear, K.G., Blowes, D.W., Ptacek, C.J., 2009. Mineralogical, geochemical, and microbial investigation of a sulfide-rich tailings deposit characterized by neutral drainage. Appl. Geochem. 24, 2212-2221.

Lv, L., Sun, P., Gu, Z., Du, H., Pang, X., Tao, X., Xu, R., Xu, L., 2009. Removal of chloride ion from aqueous solution by $\mathrm{ZnAl}-\mathrm{NO}_{3}$ layered double hydroxides as anionexchanger. J. Hazard Mater. 161, 1444-1449.
Medas, D., De Giudici, G., Podda, F., Meneghini, C., Lattanzi, P., 2014a. Apparent energy of hydrated biomineral surface and apparent solubility constant: an investigation of hydrozincite. Geochim. Cosmochim. Acta 140, 349-364.

Medas, D., Lattanzi, P., Podda, F., Meneghini, C., Trapananti, A., Sprocati, A.R., Casu, M. A., Musu, E., De Giudici, G., 2014b. The amorphous Zn biomineralization at Naracauli stream, Sardinia: electron microscopy and X-ray absorption spectroscopy. Environ. Sci. Pollut. Res. 21, 6775-6782.

Meneghini, C., Bardelli, F., Mobilio, S., 2012. ESTRA-FitEXA: a software package for EXAFS data analysis. Nucl. Instrum. Methods Phys. Res. Sect. B Beam Interact. Mater. Atoms 285, 153-157.

Nordstrom, D.K., 1977. Thermochemical redox equilibria of ZoBell's solution. Geochim. Cosmochim. Acta 41, 1835-1841.

Nordstrom, D.K., Blowes, D.W., Ptacek, C.J., 2015. Hydrogeochemistry and microbiology of mine drainage: an update. Appl. Geochem. 57, 3-16.

Park, I., Tabelin, C.B., Jeon, S., Li, X., Seno, K., Ito, M., Hiroyoshi, N., 2019. A review of recent strategies for acid mine drainage prevention and mine tailings recycling. Chemosphere 219, 588-606.

Park, M., Choi, C.L., Seo, Y.J., Yeo, S.K., Choi, J., Komarneni, S., Lee, J.H., 2007. Reactions of $\mathrm{Cu}^{2+}$ and $\mathrm{Pb}^{2+}$ with $\mathrm{Mg} / \mathrm{Al}$ layered double hydroxide. Appl. Clay Sci. $37,143-148$.

Parkhurst, D.L., Appelo, C.A.J., 1999. User's Guide to PHREEQC (Version 2) - A Computer Program for Speciation, Batch-Reaction, One-Dimensional Transport, and Inverse Geochemical Calculations. USGS Water-Resources Investigations Report, pp. 99-4259 (Denver, CO, USA).

Pillola, G.L., Leone, F., Loi, A., 1998. The Cambrian and Early Ordovician of SW Sardinia. Giornale di Geologia, vol. 60. Special lssue ECOS V/1-Sardinia Guide-book, pp. 25-38, 3.

Rehr, J.J., Albers, R.C., 2000. Theoretical approaches to x-ray absorption fine structure. Rev. Mod. Phys. 72 (3), 621-654.

Roberts, D.R., Ford, R.G., Sparks, D.L., 2003. Kinetics and mechanisms of Zn complexation on metal oxides using EXAFS spectroscopy. J. Colloid Interface Sci. 263, 364-376.

RoyChowdhury, A., Sarkar, D., Datta, R., 2015. Remediation of acid mine drainageimpacted water. Curr. Pollut. Rep. 1 (3), 131-141.

Saha, S., Sinha, A., 2018. A review on treatment of acid mine drainage with waste materials: a novel approach. Glob. Nest. J. 20 (3), 512-528.

Sanchez-España, J., Yusta, I., 2015. Low-crystallinity products of trace-metal precipitation in neutralized pit-lake waters without ferric and aluminous adsorbent: geochemical modelling and mineralogical analysis. Mineral. Mag. 79 (3), 781-798.

Sanchez-España, J., Yusta, I., 2019. Coprecipitation of $\mathrm{Co}^{2+}, \mathrm{Ni}^{2+}$ and $\mathrm{Zn}^{2+}$ with $\mathrm{Mn}$ (III/ IV) oxides formed in metal-rich mine waters. Minerals 9, 226.

Sanchez-España, J., Reyes, J., 2019. Comparing schwertmannite and hydrobasaluminite dissolution in ammonium oxalate ( $\mathrm{pH}$ 3.0): implications for metal speciation studies by sequential extraction. Minerals 9,57 .

Scheinost, A.C., Sparks, D.L., 2000. Formation of layered single- and double-metal hydroxides precipitates at the mineral/water interface: a multiple-scattering XAFS analysis. J. Colloid Interface Sci. 223, 167-178.

Seron, A., Delorme, F., 2008. Synthesis of layered double hydroxides (LDHs) with varying $\mathrm{pH}$ : a valuable contribution to the study of $\mathrm{Mg} / \mathrm{Al} \mathrm{LDH}$ formation mechanism. J. Phys. Chem. Solids 69, 1088-1090.

Shannon, R.D., 1976. Revised effective ionic radii and systematic studies of interatomic distances in halides and chalcogenides. Acta Crystallogr. Sect. A 32, 751-767.

Sheoran, A.S., Sheoran, V., 2006. Heavy metal removal mechanism of acid mine drainage in wetlands: a critical review. Miner. Eng. 19, 105-116.

Skousen, J., Zipper, C.E., Rose, A., Ziemkiewicz, P.F., Nairn, R., McDonald, L.M., Kleinmann, R.L., 2017. Review of passive systems for acid mine drainage treatment. Mine Water Environ. 36, 133-153.

Smith, K.S., 1999. Metal sorption on mineral surfaces: an overview with examples relating to mineral deposits. In: Plumlee, G.S., Logsdon, M.J. (Eds.), The Environmental Geochemistry of Mineral Deposits. Part A: Processes, Techniques, and Health Issues. Reviews in Economic Geology, 6A. Society of Economic Geologists, Inc., pp. 161-182. Chap. 7.

Starcher, A.N., Elzinga, E.J., Sparks, D.L., 2017. Formation of a mixed Fe(II)-Zn-Al layered hydroxide: effects of Zn co-sorption on Fe(II) layered hydroxide formation and kinetics. Chem. Geol. 464, 46-56.

Trainor, T.P., Brown, G.E., Parks, G.A., 2000. Adsorption and precipitation of aqueous Zn (II) on alumina powders. J. Colloid Interface Sci. 231, 359-372.

Witzke, T., Raade, G., 2000. Zincowoodwardite $\left[\mathrm{Zn}_{1-\mathrm{x}} \mathrm{Al}_{\mathrm{x}}\left(\mathrm{SO}_{4}\right)_{\mathrm{x} / 2}(\mathrm{OH})_{2} \cdot\left(\mathrm{H}_{2} \mathrm{O}\right)_{\mathrm{n}}\right]$, a new mineral of the hydrotalcite group. Neues Jahrb. Mineral.-Mon.hefte 10, 455-465.

Zhao, D., Sheng, G., Hu, J., Chen, C., Wang, X., 2011. The adsorption of Pb(II) on $\mathrm{Mg}_{2} \mathrm{Al}$ layered double hydroxide. Chem. Eng. J. 171, 167-174. 